\title{
SMARTPHONES NO ENSINO: APLICAÇÃO DE GÊNEROS DIGITAIS EM INTERFACES MÓVEIS
}

\author{
Lafayette Batista Melo, IFPB, lafagoo@gmail.com
}

\begin{abstract}
RESUMO: O trabalho mostra possibilidades de uso dos gêneros digitais pedagógicos através de padrões de interface predefinidos. A partir da produção de um web site móvel do professor, são elaborados gêneros (testes, exercícios, resumos de aulas, etc.) e é feita uma aplicação com os alunos. Os dados são validados, avaliando-se o uso dos alunos em situações pedagógicas reais e é aplicado um questionário de satisfação. Conclui-se sobre limites da ferramenta na produção de gêneros acadêmicos, consequências de alunos portarem um suporte móvel e como gêneros acadêmicos são reelaborados não só durante a leitura, mas também em função do que é definido na produção do web site.
\end{abstract}

Palavras-chave: gêneros digitais, interfaces móveis, smartphones.

\section{SMARTPHONES IN EDUCATION: APLICCATION OF DIGITAL GENRES IN MOBILE INTERFACES}

\begin{abstract}
The work shows possible uses of educational digital genres through predefined interface standards. From the production of a mobile professor web site, genres are prepared (tests, exercises, lesson summaries, etc.) and an application with the students is made. Data is validated, evaluating the use of students in actual teaching situations and a questionnaire of satisfaction is applied. There are conclusions about: limits of the tool in the production of academic genres, consequences of use of a mobile support and how academic genres are reworked not only for reading, but also in terms of what is defined in the production of the web site.
\end{abstract}

Key words: digital genres, mobile interfaces, smartphones.

\section{INTRODUÇÃO}

Este trabalho tem uma preocupação inicial de relacionar as áreas de linguística e interação humano-computador no intuito de entender como são usados os smartphones em uma aplicação de um web site móvel do professor para dar suporte às aulas. A preocupação do trabalho deve-se a dúvidas sobre como usos, especialmente de apps e web sites móveis, ocorrem em um mundo rodeado de gêneros digitais no campo educacional. Em linguística, há ênfase no estudo da linguagem em práticas reais e, em interação humano-computador, muitas pesquisas estão voltadas para a usabilidade e os padrões de interface. Pretende-se integrar as duas áreas, envolvendo a linguagem em contexto de uso real com estudos sobre padrões de interface, especialmente relacionados ao comportamento do usuário e ao mundo da mobilidade.

Consideremos a seguinte narração: um aluno pode até chegar em casa, deitar em sua cama prestes a dormir, lembrar que tem alguma atividade atrasada e, então, se levantar para ligar seu computador desktop, esperando a inicialização e abrindo vários programas. Como sabemos que a realidade não funciona como na historinha descrita, já que muitos alunos simplesmente verificariam no smartphone se há alguma mensagem, 
esta pesquisa vai mostrar como um conjunto de gêneros pedagógicos pode participar da vida acadêmica e suas consequências. Ou seja, há diversas situações nas quais alguém observa imediatamente seu celular para manipular aplicativos e acessar a internet, mas, no campo do ensino, poucos trabalhos parecem verificar como isso ocorre. Isso motiva a produzir um material pedagógico digital, aplicá-lo com os alunos, para só depois analisar os resultados das aplicações, e quais são as características na mobilização de gêneros pedagógicos.

Vendo por outro lado, o uso de smartphones por professor e alunos está subjugado a projetos de apps e web sites cuja consequência mais imediata para o usuário é encontrada na manipulação da interface. Certos padrões de menus ou de visualização de um vídeo em dispositivos móveis são diferentes da versão desktop e os usuários precisam também aprender a usá-los. O touch screen e o fato de se estar em qualquer lugar, que pode ser a rua ou a cama no momento de dormir, são problemáticas reais a serem consideradas na execução de um projeto.

Assim, esta pesquisa demonstrará uma atividade completa e com práticas reais (não simuladas), considerando o que há disponível em relação à orientação sobre padrões de interface e ferramentas que tornem possível ao professor executar rapidamente o seu projeto.

O objetivo principal do trabalho é mostrar possibilidades de uso dos gêneros digitais pedagógicos através de padrões de interface predefinidos em dispositivos móveis, especialmente celulares. Tais possibilidades devem ser vislumbradas em um conjunto completo de tarefas que envolvem: definição dos gêneros a serem produzidos nos smartphones, escolha de ferramentas atuais para produção do material pedagógico a ser utilizado pelos alunos, avaliação das ferramentas que obedecem aos melhores padrões de interface, distribuição do material produzido na ferramenta escolhida para uso em necessidades reais de uma disciplina, análise da satisfação dos alunos por meio de questionário e análise de como os gêneros produzidos se adequaram aos padrões. Assim, pretende-se contribuir com a realização de novos projetos em outras disciplinas para novos relatos de experiência e lançar questionamentos, do ponto de vista científico, sobre a abordagem de gêneros em línguística e sobre trabalhos baseados em projetos de padrões de interface.

A seguir, na seção 2, discute-se um pouco mais as abordagens de gêneros em linguística e dos padrões de interface em interação humano-computador. Na seção 3, mostra-se como as ferramentas de produção foram escolhidas para o professor, adequando-as aos padrões vigentes e às necessidade de produção de gêneros na disciplina, em um site feito especificamente para smartphones. Na seção 4, é descrita a metodologia de aplicação, com as etapas em geral do projeto e o acompanhamento de uso, por parte dos alunos, do site do professor. Na seção 5, é descrita a aplicação de um pequeno questionário de satisfação com os alunos. Na seção 6, é feita uma análise, considerando toda a atividade, do planejamento à aplicação, bem como o questionário aplicado, com orientação de alguns resultados. Finalmente, na seção 7, são feitas algumas conclusões e considerações finais com vista a novos projetos e relatos de experiência.

\section{PERSPECTIVAS DOS GÊNEROS DIGITAIS E DOS PADRÕES DE INTERFACE}

A pesquisa sobre gêneros, especialmente os digitais, tem crescido amplamente na área dos estudos da linguagem, mais até na linguística do que na literatura. Contudo, a noção de gêneros em linguística não deve ser utilizada como mero instrumento classificatório, 
mas como uma forma viva da atividade textual ou discursiva. Marcuschi (2008) diz que gêneros são eventos textuais maleáveis, que surgem ligados a necessidades e atividades sócio-culturais, bem como na relação com inovações tecnológicas. Assim, podemos ver que os gêneros são vistos como atividades comunicativas e sempre associados às condições sócio-históricas. Enfatiza-se, portanto, que tais condições têm hoje muito a ver com as possibilidades tecnológicas. Em uma sala de aula, tratando-se dos gêneros mais tradicionais como uma aula expositiva ou mesmo de um blog para que alunos e professores debatam sobre um conteúdo, há modos de trabalhá-los os integrando à internet e ao mundo dos dispositivos móveis. Dentre esses dispositivos, os que mais são utilizados são os smartphones, celulares com acesso à internet, o que traz ainda mais motivação para levar os gêneros do ensino institucionalizado ao encontro do mundo da mobilidade.

Marcuschi (2008) trata também da noção de suporte, que seria como um "portador de texto", um locus físico ou virtual que serve de base de fixação do gênero materializado como texto. Tais ideias se aproximam do conceito de interface, já que não são apenas referentes ao texto na tela, mas também aos menus, botões, links e tudo o que dá acesso a novas funcionalidades. Tradicionalmente, uma interface homemmáquina é a parte de um artefato que permite a um usuário controlar e avaliar o funcionamento deste artefato através de dispositivos sensíveis às suas ações e capazes de estimular sua percepção, (Norman, 1986). De acordo com Preece (2011), a interface humano-computador está relacionada ao entendimento de como as pessoas usam sistemas computacionais para que sistemas possam ser projetados para atender melhor às necessidades dos usuários. Hoje em dia, os estudos de interface se aprofundam bastante nos padrões de projeto, os quais devem ser reconhecidos no uso dos dispositivos físicos, independentemente do sistema ou dos dispositivos. Assim, esta pesquisa procurou ferramentas que gerassem interfaces baseadas nos padrões adotados atualmente.

Por outro lado, mesmo que os estudos da área de interação humano-computador tenham suas contribuições, como na busca por padrões, não há tanto um atendimento às modificações e misturas que podem ocorrer nos vários gêneros digitais. Ou seja, os conceitos de suporte de gêneros e o estudo de como se transformam e circulam merece uma elaboração maior. A ideia de intergenericidade tem se mostrado insuficiente para entender o funcionamento dos gêneros, como é apontado em trabalhos como os de Costa (2011) e Lima-Neto (2012). Tem sido inclusive preferível o termo mescla ou reelaboração em vez de mutação de gêneros, devido a novas traduções da obra de Bakhtin. A intergenericidade seria apenas uma das maneiras de misturar gêneros e seria muito pobre ver essas misturas apenas como relação entre forma e função social, sendo esta sempre prevalecida. De todo modo, há mudanças que fazem com que compreendamos como funcionam os gêneros também segundo seus condicionantes tecnológicos e históricos. Um suporte como um jornal seria talvez mais importante para compreender um gênero como o editorial do que suas relações forma/função. Semelhantemente, a interface de um e-mail é imediatamente compreendida de maneira diferente de uma planilha ou de uma seção do Facebook. Por conta disso, há um paralelo entre interface e suporte (a diferença é que a interface não é apenas para textos, mas também para componentes que podem ser programados e sofrem ação direta do usuário). Nesse sentido, os estudos de Costa (2011) e Lima-Neto (2012) fornecem subsídios para compreender as várias formas de reelaboração de gêneros e ao mesmo tempo não negam que há padrões de interface. Desse modo, procurar-se-á mostrar adiante as ferramentas que permitem ao professor gerar interfaces baseadas em padrões para a construção de gêneros pedagógicos a serem utilizados em dispositivos móveis. 
Em outras palavras, foi feita uma extensa pesquisa das ferramentas que geram padrões atualizados, de modo a ser produzido pelo professor um conjunto de gêneros reconhecíveis tanto pela sua função quanto pela forma mais adequada de serem manipulados através de celulares. Assim, o estudo sobre o uso e sua adequação e satisfação com os alunos é feito em etapa posterior, considerando se há utilização eficaz mesmo dentro de possíveis reelaborações de gêneros por intermédio dos dispositivos.

\section{PADRÕES E FERRAMENTAS PARA A CONSTRUÇÃO DE WEB SITES MÓVEIS}

Para que os resultados ficassem o mais próximo possível de serem adaptados para novas aplicações com professores e alunos, esta pesquisa optou por fazer um levantamento de ferramentas gratuitas existentes atualmente, identificando se elas seguem os padrões de interface e investigando os recursos apropriados para a produção de gêneros já existentes nas ferramentas (uso de vídeos para explicar um assunto, produção de exercícios com resposta objetivas ou subjetivas, espaço para mostrar definições e conceitos resumidos das aulas, etc.).

Os padrões, seguindo Tidwell (2011) e Neil (2012), foram checados nas ferramentas em termos de padrões de comportamento dos usuários e padrões para interfaces móveis.

Os padrões de comportamento que o site ou app devem seguir incluem, entre outros:

- Exploração segura - a interface deve dar segurança ao usuário. Exemplo: um usuário que quer tratar uma imagem e pode desfazer várias vezes o efeito de suas ações sem comprometer a imagem original.

- Gratificação instantânea - as pessoas gostam de ver resultados imediatos para as operações que realizam e as funcionalidades não podem ser ocultadas.

- “SATISFICIÊNCIA” - usuários não leem metodicamente tudo que está na interface. Eles usam aquilo que é imediatamente satisfatório e isso deve ser considerado.

- Mudanças no meio do caminho - qualquer usuário está propenso a mudar de ideia no meio do caminho em que suas ações estão sendo desenvolvidas e voltar atrás. Exemplo: ao preencher um formulário ou assistir um vídeo, a interface deve continuar indicando outras atividades.

- Escolhas adiadas - se você pedir algo desnecessário ao usuário enquanto ele estiver realizando uma tarefa, ele vai preferir adiá-la.

- Construção incremental - quando as pessoas estão criando algo não fazem tudo em uma ordem precisa.

- "Habituação" - quando uma interface é usada por muito tempo, algumas de suas ações se tornam reflexivas (CTRL-S ou botão de voltar, por exemplo).

- Micro paradas - considerar que as pessoas podem parar de fazer uma tarefa para depois voltar e continuar, como na checagem de e-mails no meio tempo em que se está realizando outras tarefas. Isso deve ser considerado sobretudo em dispositivos móveis.

- Memória espacial - quando as pessoas manipulam objetos, frequentemente os encontra mais tarde e a interface deve deixar pistas para relembrar como fazer a última ação.

Já os padrões para interfaces móveis devem incluir, entre outros: 
- Pilha Vertical (Vertical Stack) - ordenação dos conteúdos em uma coluna vertical com o mínimo de uso de elementos lado a lado.

- Filmstrip - organização de páginas lado a lado.

- Ferramentas de toque - recurso apenas em resposta e sobrepostos ao conteúdo.

- Bordas generosas - margens largas com espaço em branco ao lado de botões e links e áreas de toque.

- Apps ricamente conectados - links diretos para os apps. Por exemplo, de vídeos para o Youtube.

- Marca simplificada - logo, cores e outras marcas pequenos e rápidos de carregar.

Há vários outros padrões na literatura, mas não é objetivo desta pesquisa fazer uma relação extensa dos mesmos e sim dizer como eles foram checados e em quais ferramentas. Das ferramentas analisadas para a produção dos gêneros e identificação se seguem ou não os padrões, foram investigadas as seguintes, na tabela 1, com seus respectivos endereços na web:

Tabela 1 - ferramentas

\begin{tabular}{|l|l|}
\hline Ferramenta & Endereço \\
\hline Holly Cow & http://holycowapps.com/ \\
Lianja & http://www.lianja.com/ \\
DroidGenerator & http://droidgenerator.com/ \\
SkyBuilder & http://skybuilder.net/ \\
TapCrowd & http://www.tapcrowd.com \\
AppsGeyser & http://www.appsgeyser.com/ \\
BuzzTouch & http://www.buzztouch.com/ \\
AppsBar & http://www.appsbar.com \\
WizardApp & http://www.mobileappwizard.com/ \\
Appsbuilder & http://www.apps-builder.com/en/home \\
Onbile & http://www.onbile.com/ \\
Mimplt & http://mimpit.com.br/ \\
Andromo & http://andromo.com/ \\
HAC & http://www.hypernextandroid.com/ \\
Learncast & http://www.learncast.com/ \\
APPMK & http://www.appmk.com/ \\
Mobile Test & http://www.mobiletest.es/index.html \\
The AppBuilder & http://www.theappbuilder.com// \\
Mobile Roadie & http://mobileroadie.com/ \\
Appacelerator & http://www.appcelerator.com/ \\
Mobione & http://www.genuitec.com/mobile/ \\
App Maker for Android & http://www.appmakr.com/ \\
Duda Mobile & http://www.dudamobile.com/ \\
\hline
\end{tabular}

Foi verificado que algumas ferramentas pareciam ser gratuitas, mas, ao final, pediam uma taxa para publicação do site móvel. Outras diziam produzir apps e web sites, mas só geravam apps. Algumas delas pareciam já ter formatos de exercícios prontos (de questões objetivas ou subjetivas), mas, na verdade, também precisavam de uma valor adicional para serem integradas aos sites. Alguns sites das ferramentas ficavam fora do ar ou interrompiam suas atividades. Em virtude dessas questões, naquele instante, foi escolhida a ferramenta Duda Mobile, que não necessitou de conhecimento de programação, atendia aos padrões de comportamento e de mobilidade 
estudados e tornou possível tanto a geração quanto a publicação do web site do professor em todos os gêneros necessários para a pesquisa e para a realidade da aula. Além disso, a ferramenta Duda Mobile foi usada no modo on-line para produzir o web site do professor, ou seja, sem qualquer necessidade de baixar programas para o computador. O Duda Mobile é de fácil usabilidade, basicamente oferecendo algumas telas padrão para celulares, que podem ser usadas conforme a necessidade e modificadas rapidamente. Por exemplo, para produzir uma tela de apresentação com título e texto, arrasta-se uma das telas padrão que a própria ferramenta sugere para uma área de edição e modifica-se o texto. Para uma tela do celular que rode um vídeo, basta arrastar a tela padrão de vídeo e, no modo de edição, digitar o endereço do vídeo no Youtube que realmente se deseja rodar. Em suma, todos os padrões de comportamento e mobilidade são atendidos. Adiante, na figura 1, telas de layout padrão que podem ser arrastadas para o modo de edição à direita, cuja versão final é modificada diretamente.

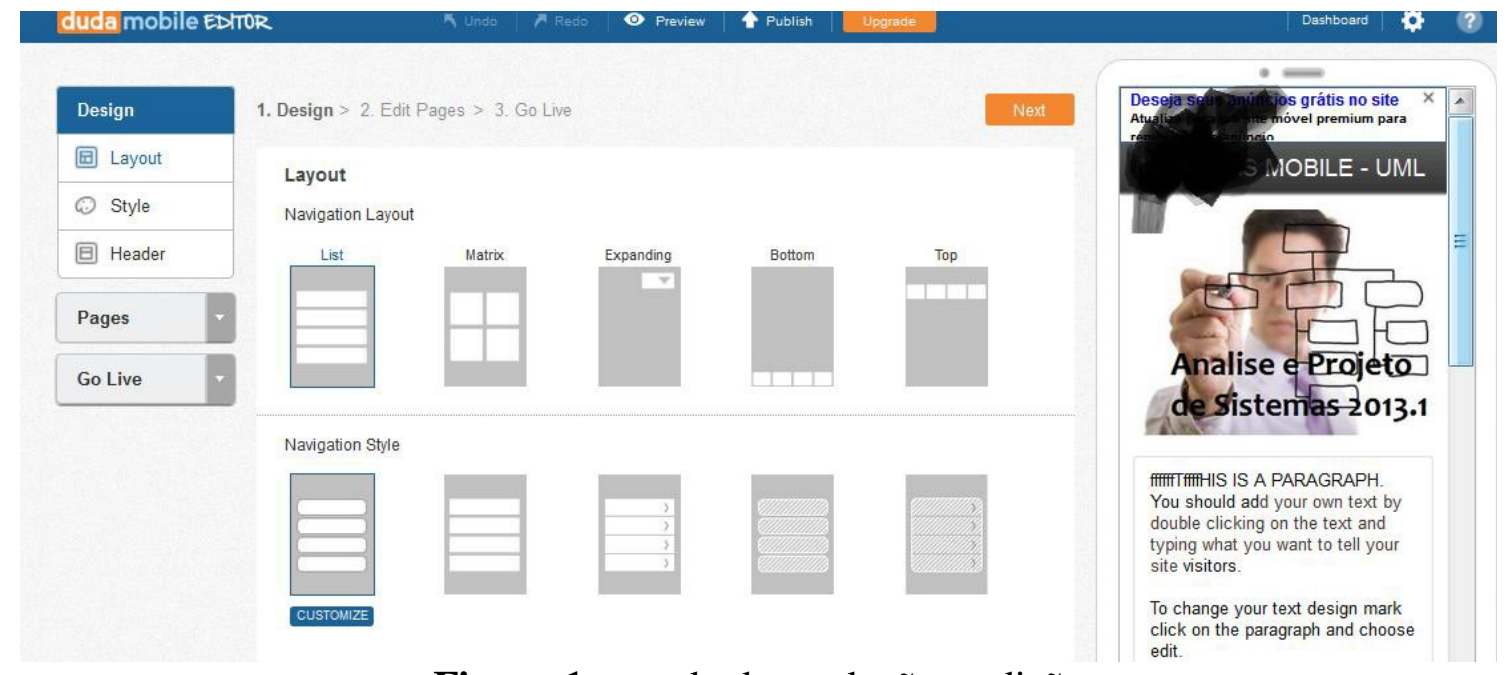

Figura 1 - modo de produção e edição

Foi produzido um material com tela de apresentação da disciplina, resumo dos conteúdos, dicas sobre a matéria sobre dúvidas gerais e problemas recorrentes nos exercícios e provas (complemento das aulas expositivas), um exercício resolvido em vídeo, um teste objetivo com questões de marcar e uma tela final de contato com o professor. Este material se constitui como um web site do professor e algumas de suas telas estão na figura 2 (mostrando, respectivamente, a tela de apresentação, as opções do menu principal, um resumo com explicação de matéria das aulas, um vídeo com um exercício resolvido e um teste com questões de marcar), ou seja, contemplando os vários genéricos acadêmicos digitais requeridos para a disciplina. 


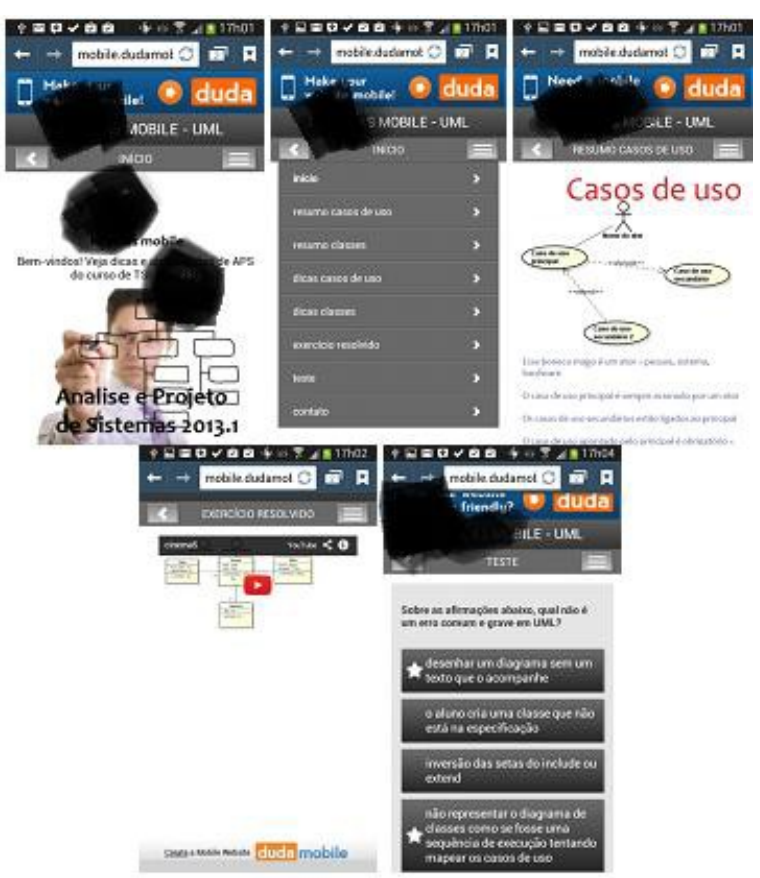

Figura 2 - web site do professor

\section{COMO O EXPERIMENTO FOI REALIZADO}

A metodologia de execução de todo o trabalho pode ser resumida de acordo com as seguintes etapas:

1 - análise dos padrões, das ferramentas disponíveis gratuitamente no momento e que não precisem de conhecimento de programação (através de pesquisas no Google) e definição da disciplina com cujos gêneros se vai trabalhar - o estudo dos padrões e das ferramentas foi feito conforme descrição nas seções 1 e 2. Para esta aplicação, foi definida a disciplina de Análise e Projeto de Sistemas do período 2013.1. No contexto real de produção, observou-se a necessidade de se criar mini-aulas expositivas, seções de dúvidas, gabarito de exercício e dicas, especialmente para ajudar em pontos cruciais antes da prova. É importante ressaltar que os gêneros envolvidos foram produzidos para serem trabalhados conforme as necessidades reais da disciplina. Não foi uma experimentação à parte.

2 - uso de uma ferramenta para construção do web site móvel do professor a ser utilizado pelos alunos - para esta aplicação, foi escolhida a ferramenta DUDAMOBILE, conforme razões expostas na seção 2.

3 - publicação do web site do professor para uso móvel pelos alunos e divulgação em mensagens de texto ou pelo whatsapp - a própria ferramenta tem uma funcionalidade de publicação do site na web. Para que todos os alunos realmente experimentassem o conteúdo e relatassem fidedignamente como o utilizaram em um dispositivo móvel, foram requisitados todos os números dos seus celulares e foi fornecido, ou pelo aplicativo whatsapp ou através de mensagens de texto, a URL (endereço) do web site, de modo a minimizar a possibilidade de os alunos o testarem via desktop (o que não corresponderia ao objetivo da pesquisa de trabalhar especialmente com celulares).

4 - aplicação de um questionário com os alunos.

5 - avaliação da produção e do uso.

As etapas 4 e 5 merecem maiores explicações nas duas seções adiante. 


\section{COMO FOI AVALIADO O USO}

Foi elaborado um questionário, o qual foi aplicado com os alunos, de modo que se averiguassem relatos do uso real, para melhor avaliação da eficácia e da maneira como os gêneros foram tratados. O questionário é simples, composto de sete itens. No primeiro item, pergunta-se sobre qual é o modelo do aparelho, o sistema e a versão. Além disso, pede-se para que o aluno faça uma descrição da experiência de uso - em qual local (banheiro, cama, fila de banco, sala de jantar, etc.) - e relate se houve interferência de alguma forma no que era feito no momento e como. As demais perguntas foram respondidas em uma escala de concordância e o resultado foi obtido conforme a tabela 2, com valores em percentual aproximado.

Tabela 2 - questionário

\begin{tabular}{|c|c|c|c|c|}
\hline Questionário & 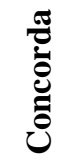 & 疍 & 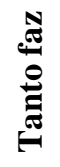 & 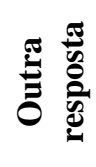 \\
\hline O material serve como um complemento para as aulas & 100 & 0 & 0 & 0 \\
\hline Seria melhor um App do que um Website Mobile & 50 & 50 & 0 & 0 \\
\hline $\begin{array}{l}\text { Dicas, testes, explicações, exercícios e outras atividades da } \\
\text { disciplina deveriam ter sido feitos no mesmo formato que é feito } \\
\text { em sala de aula ou no nosso grupo do Facebook, sem precisar de } \\
\text { adequações }\end{array}$ & 30 & 70 & 0 & 0 \\
\hline A usabilidade do material é diferente de usar um site em desktop & 20 & 0 & 80 & 0 \\
\hline $\begin{array}{l}\text { Gostaria que todo o conteúdo da disciplina estivesse também em } \\
\text { uma versão mobile }\end{array}$ & 80 & 0 & 20 & 0 \\
\hline $\begin{array}{l}\text { A experiência me ajudou a aprender melhor e me preparar para } \\
\text { prova }\end{array}$ & 100 & 0 & 0 & 0 \\
\hline
\end{tabular}

Dentre os relatos de uso em relação à localização e se interferiu em alguma tarefa, há respostas bem variadas: alguns usaram na cozinha enquanto preparavam o jantar, outros no quarto, antes de dormir, e um, afirmou que usou no shopping, na fila do cinema. Um aluno também afirmou que testou o web site no carro, enquanto dirigia da escola para casa, fato que foi chamado atenção pelo professor em relação à segurança.

Pode-se notar no quadro de respostas que todos responderam que o material serve como um complemento para as aulas. Muitos alunos também pediram à parte para que novos materiais fossem produzidos para as matérias subsequentes. Do mesmo modo, todos acreditaram que a estratégia é importante para se preparar para as provas. Contudo, em relação especificamente às explicações, dúvidas, gabarito, testes e exercícios serem feitos no mesmo formato das aulas, ou em grupos do Facebook, não houve muito respaldo. Isso indica que os gêneros no seu formato especial para dispositivos móveis precisam ser considerados, independentemente de suas funções ou propósitos serem semelhantes aos daqueles utilizados regularmente sem este apoio tecnológico. Há de se considerar, porém, que tais gêneros estão no domínio do campo acadêmico. Assim, uma preparação a priori quanto aos objetivos e intuitos, a serem atingidos com os gêneros, são compartilhados na turma entre professor e alunos, mas os dispositivos e suas interfaces adotadas no modo padrão não surtiram maiores problemas. Havia expectativa de que o vídeo gabarito com um exercício resolvido não fosse bem assimilado pelos alunos, até devido à diversidade de sistemas e dispositivos, mas não ocorreu qualquer reclamação neste sentido. Em outras palavras, utilizar uma ferramenta 
que adota padrões de interface foi bastante útil para gerar todos os gêneros, mas no uso real alguns aspectos foram mais ou menos satisfatórios para os alunos, considerando especialmente o campo acadêmico em conjunto com o fator mobilidade.

\section{RESULTADOS E ALGUMAS CONSTATAÇÕES}

Podemos enumerar alguns resultados ou conclusões com suas respectivas consequências:

- há várias ferramentas gratuitas que não necessitam de conhecimento de programação para o professor produzir conteúdo de modo que ele fique mais tempo pensando como adequar o conteúdo propriamente dito do que construindo a interface ou mesmo pensando em seus padrões para produzir os vários gêneros.

- os alunos não demonstraram estranhamento para consumo do conteúdo dentro do domínio acadêmico, além de aprovarem o uso, mas a maneira como deveria ser difundido o conteúdo, independentemente do gênero, divergiu. A maioria queria que continuasse a existir uma versão móvel do conteúdo, mas aproximadamente metade preferiu que, em vez de um web site móvel, fosse produzido um app. Como o web site precisa de acesso on-line, conjecturou-se se não houve problemas de conectividade e acesso à internet, mas nenhum aluno reclamou da eficiência, nem no carregamento do vídeo. Outro estudo, comparando apps com web sites móveis, poderia fornecer melhores resultados neste sentido.

- houve reelaboração inovadora de gêneros, ou seja, mudanças ocorreram na recriação dos gêneros, mas não a partir da assimilação com outros gêneros. O gabarito em vídeo e as mini (aulas) explicativas com dicas e macetes estavam em novo formato, para dispositivos móveis específicos, seguindo padrões próprios de interface, mas foram transformados sem a participação de um segundo gênero, o que caracteriza esta reelaboração inovadora conforme Costa (2011). A eficiência com a qual os gêneros foram aplicados pode ser justificada pela obediência aos padrões e também por estarem presos ao domínio pedagógico. Outras formas de modificação parecem não estar presas a um domínio, como as misturas em vídeo que circulam nas redes sociais de uma forma mais ampla. Uma possibilidade a ser investigada é o modo como o professor trabalhou os padrões, obedecendo estritamente atividades que já fazia anteriormente. Outro professor poderia desenvolver formatos mais criativos de apresentação do conteúdo para smartphones, o que poderia ser realizado em uma pesquisa futura.

- sugere-se, portanto, que os propósitos dos gêneros estão altamente atrelados ao domínio e que possivelmente um uso dos padrões mesmo em outros domínios específicos facilitaria o uso mais do que a produção de materiais criativos e totalmente diferentes dos que eram até então empregados.

\section{CONSIDERAÇÕES FINAIS}

Esta pesquisa procurou mostrar a relação da produção de material didático digital com os gêneros digitais em uma atividade real, completa e que cumpre as necessidades concretas de professor e alunos no desenvolvimento de uma disciplina. Não apenas o modo como o projeto é desenvolvido é ressaltado no trabalho, mas suas implicações na 
vida dos alunos. Desse modo, pretende-se investigar sobre outras aplicações, seja em outros cursos e disciplinas, seja com outras ferramentas ou utilização de gêneros diferenciados. De todo modo, a integração entre assuntos das áreas de interação humano-computador e linguística foi altamente profícua para a realização de um projeto completo como este, o que instiga a que outras pesquisas, integrando as áreas, continuem a ser realizadas.

\section{REFERÊNCIAS}

MARCUSCHI, L. A. Produção textual, análise de gêneros e compreensão. São Paulo: Parábola, 2008.

COSTA, R. F. DA, ARAÚJO, J. C. A reelaboração do gênero telenovela na migração entre suportes visuais. In: Anais do VII Congresso Internacional da ABRALIN, 2011. Curitiba, Anais. Curitiba: Associação Brasileira de Linguística, 2011.

LIMA-NETO, V. de, Araújo, J. C. Por uma rediscussão do conceito de intergenericidade: Linguagem em discurso, V. 12, N. 1, 2012.

PREECE, J., ROGERS, Y., SHARP, H. Interaction design: beyond human-computer interaction. EUA: Willey, 2011.

TIDWELL, Jenifer. Designing Interfaces. Canada: Ed. O’Reilly, 2011.

NEIL, Theresa. Padrões de design para aplicativos móveis. São Paulo: O’Reilly, 2012

NORMAN, D. Cognitive Engineering. In: D. Norman \& S. Draper (Ed.). User Centered System Design. Hillsdale, NJ: Lawrence Erlbaum, 1986. p. 31-61. 